\title{
Managerial Practices for Increasing Perceived Fairness in Interorganiza- tional Projects
}

\author{
Bhaskar Prasad*, Rudy Martens and Paul Matthyssens
}

University of Antwerp, Belgium

\begin{abstract}
The aim of this paper is to identify which managerial practices are required to achieve perceived fairness. The paper is based on a literature review and a dyadic case study on an innovative development project. The analysis shows how perceived fairness can be stimulated by managerial practices. It emphasizes the importance of attending to the multiple dimensions of perceived fairness in the concesption and execution of these managerial practices. The paper contributes to the literature on fairness and organization by offering a testable framework in which the concept of perceived fairness is refined.
\end{abstract}

Keywords: Inter-organizational projects, Managerial practices, Perceived fairness.

\section{INTRODUCTION}

Recently, there has been a growing recognition of the significance and necessity of inter-organizational projects [1]. Organizations are in need of obtaining information and knowledge from outside their own boundaries in order to be able to develop new technologies and working methods [2]. A fundamental requirement for inter-organizational projects, which is particularly instrumental in guiding alliance parties' behavior and contribution to interparty exchanges, is the perception of fairness defined as a tripartite concept consisting distributive, procedural and interactional justice [3]. Depending on each the type fairness of outcome distributions, fairness of procedures to determine the outcome distribution and fairness of interpersonal treatment received during the enactment of organizational decisions and procedures become critical.

The perception of fairness creates a strong foundation for interparty cooperation and for the kind of evolving cooperation needed in an inter-organzational project [4]. It allows those involved to transcend inter-organizational rivalry and to cooperate in projects.

This study aims to gain insight into the managerial practices that affect perceived fairness. Managerial practices involve the activities covering the utilization of people, technologies and procedures to solve problems and to achieve specific objectives [5,6]. Managerial practices can be used by managers in inter-organizational projects to influence the perception of fairness. A comprehensive discussion of fairness should include the different types of fairness such as distributive, procedural and interactional justice $[3,7,8]$. Based on theories obtained from the areas of organizational justice these three types of fairness will be examined in depth.

*Address correspondence to this author at the 404, Mytri Palace, 6th Main, 20th Cross, N.S. Palya, BTM 2nd Stage, Bangalore 560076, India;

Tel: 00917795078003; E-Mail: jbhaskarp@gmail.com

\section{RESEARCH PROBLEM}

Studies on inter-organizational projects have put forward theories on the motives of collaborative and interim working relationships [2]. A major motivation is related to learning, which in terms of accessing and acquiring critical information or capabilities from the partner is often stated to be one of the foremost motivations for inter-organizational projects [9]. Though studies do reveal that such project partnerships can be useful, it has been observed that on several occasions such partnerships do not succeed [10,11]. Considering this paradox, more studies on the factors associated with partnership success are needed. Researchers do confirm that perception of fairness can lead to -and is a necessary condition forcooperative behavior among individuals, groups or organizations [12]. Particularly in inter-organizational project studies, perceived fairness is an important area of investigation, because an exchange can be regarded as unfair by the collaborating partners, with impending negative outcomes [13]. The effect of perceived fairness upon the performance of the inter-organizational projects has been investigated and found to be a positive contributor [14]. Consequently it will be useful to have a better insight in the managerial practices facilitating perception of fairness in inter-organizational projects.

Hence the following research question is formulated: Which managerial practices result in an increased level of perceived fairness in inter-organizational projects?

\section{FAIRNESS TYPES}

A fair process profoundly influences attitudes and behaviors critical to projects. The fairness theory offers a comprehensive framework for understanding the factors that influence how members interpret the procedures, interpersonal interactions, and information received during project activities [15]. Research studies suggest that three different types of organizational justice should be distinguished, namely distributive, procedural and interactional justice [3]. 


\section{Distributive Justice}

Distributive justice relates to the fairness of an outcome. Participants who perceive the benefits of an outcome to be commensurate with their inputs perceive distributive justice to be present [15]. In the specific setting of interorganizational projects, the distributive justice can be the extent to which interparty sharing of the rewards from cooperation is fair in view of each party's contribution, commitment, and assumption of responsibility [3]. Rewards can be monetary as well as nonmonetary. Generally, monetary reward sharing is more likely to be specified in a contract than nonmonetary gain distribution. Therefore, when project managers consider nonmonetary rewards, their assessment of distributive justice is typically more perceptual [12]. This perception is strengthened by the fact that parties attach varying weights to different aspects of rewards and that the real contribution of each member to project activities does not always coincide with ownership distribution. Distributive justice is the degree to which a member's real gains accord with his contribution, ongoing commitment to the project, and risk or responsibility bearing throughout the course of the project $[16,17]$. It is critical to maintain a high level of distributive justice perception in an alliance context to minimize the negative reactions to perceived unfairness [18].

The earliest theory of distributive justice can be attributed to equity theory [19]. According to equity theory, we are interested in how much we get relative to how much we contribute [20]. Thus as per the equity principle, outcomes should be distributed based on the contribution of individuals [13]. Therefore the individual who make a larger contribution should receive a larger reward. There is more to distributive justice than equity. The second principle promotes equality of distributions where each employee is provided roughly the same reward [21]. While equity tends to provide individual rewards for high performance, equality tends to build esprit de corps among teammates [22].

\section{Procedural Justice}

The domain encompassed by fairness or justice theory is broader than outcome alone. The procedures that lead to an outcome are also an important consideration when assessing perceived fairness [15]. They labeled this aspect procedural justice. Even if distributive justice-that is, a fair outcomeis not experienced in a transaction, members who perceive high procedural justice could believe that the unfair outcome was merely a coincidence and could expect distributive justice to occur the next time [15]. In an inter-organizational project, procedural justice can be the extent to which the decision-making process and procedures that affect each member's interests are impartial and fair as perceived by the members. Managers need to be aware that fairness can occur when the procedures used in the decisions and their execution is transparent, adjustable, and correctable [16, 3]. In addition, the procedures have to be unbiased, representative, and nondiscriminatory to each member. The ability to voice one's opinions through the decision process and also the possibility to have an impact on the result are seen to have a sound influence on the perception of procedural justice [23]. It has been shown that the perceptions of procedural fairness strengthen individuals' commitment to the activities [24].
Three criteria have been established to encapsulate the perception of procedural justice in business settings, namely, engagement, explanation, and clarity of expectations [25]. The involvement of individuals in decisions that affect them by both asking for their input and allowing them to refute the merits of one another's ideas and assumptions is called engagement [26]. Explanation means that each member engaged and concerned with the project should understand why the decisions are made as they are and why certain ideas and inputs may have been overridden in ultimate decisions [27]. Clarity of expectations requires that before, during, and after decisions are made members have a definite appreciation of what is expected of them [25]. Taken together, these three criteria - engagement, explanation, and clarity of expectations - collectively capture the domain of procedural justice.

\section{Interactional Justice}

While procedural justice refers to the process and is about the system, interactional justice refers to individuals' actions and behaviors occurring during the procedures [8] suggest that the conduct of those who enact the procedures influences the outcome and should be labeled interactional justice. According to [8] interactional justice includes four criteria: (1) justification (providing explanations so participants understand the rationale behind decisions); (2) truthfulness or frankness; (3) respect (behaving politely); and (4) propriety (behaving appropriately). Thus in interactional justice, the focus is on individuals' perceptions of the quality of interpersonal treatment received during the enactment of organizational decisions and procedures and includes various human-side behaviors displaying social sensitivity, such as respect, honesty and politeness, performed by the originator of justice toward the recipient of justice [28]. So when procedural justice emphasizes on the formal aspect of the exchange process, interactional justice focuses on the social aspect of the process [29]. A basic norm is that individuals usually reciprocate the benefits they receive from others, ensuring ongoing supportive exchanges. Information sharing can be facilitated by a strong sense of reciprocity in which favors are given and favors received along with a strong sense of fairness [16].

Thus a person is interactionally just if he or she appropriately shares information and avoids offensive remarks [20]. In other words, there are two aspects of interactional justice [22]. The first part, sometimes called informational justice refers to whether one provides adequate justifications when things proceed in an unfavourable manner [30,31]. The second part, sometimes called interpersonal justice, refers to the respect and dignity with which one treats another [30, 23]. Thus when the interpersonal justice captures the degree to which people are treated with politeness, dignity, and respect by decision makers, whereas informational justice concerns the explanations provided to convey the reasoning behind processes and outcomes [21].

Though taking care of the three components of fairness at the same time can be a useful task, but it can also be diffiuclt. The point to be noted is that evidence suggests that the three components of justice interact [32]. Though this interaction can be described in different ways, the key point is that the negative effects of lack of fairness can be at least partially mitigated if at least one component of fairness is 
maintained $[33,20]$. For instance, the distributive and the procedural injustice will have lesser negative consequence if the interactional justice is high. Distributive, procedural, and interactional justice could be correlated [33, 32]. For the managerial practices to be effective they need to actively influence all the above three aspects of fairness. They can utilize procedural justice to encourage cooperation, as it is particularly instrumental in creating standards and norms of expected behavior. These norms facilitate daily exchanges and routine operations and can ensure the building of relationships. By means of distributive justice the members' motivation for exchange of information becomes keener since there will be higher levels of assurance in unbiased distribution of gains. Through improved relationships and mutual learning induced by managers, interactional justice can reduce incongruities between members in the project.

\section{MANAGERIAL PRACTICES}

The intention of an inter-organizational project is the combination of distinctive skills from different organizations with the purpose of realizing synergy between diverse competences [34]. The members with different competencies could have diverging perspectives of the activities to be performed in projects. In these conditions perceived fairness in interactions will become an essential requirement for the project to fuction properly. Therefore specific managerial practices should be put in place within the project with the purpose of assuring, on behalf of those managed, a perception of fairness. Building upon [5] our study conceives managerial practices as the activities covering the selection and utilization of members, technologies, and procedures by managers to solve problems and to help in accomplishing specific objectives.

Generic managerial practices can be divided into two categories namely (1) task oriented practices (2) relationship oriented practices.

Specific task-oriented behaviors include: (1) short term planning, (2) clarifying responsibilities and performance objectives, (3) monitoring operations and performance [35]. Planning practices can affect members' perceived obligations and their intention to be committed to the project, which affects their perception of fairness within the project [36]. Clarifying practices result in more transparency, adjustability and correctability within the project [37]. Monitoring can elucidate the required adopting related procedures within the project to bring out improved performance from the members [38].

Specific relationship-oriented behaviors include: (1) supporting, (2) developing, (3) recognizing, (4) consulting, and (5) empowering [35]. These practices lead to the treatment of the members with sensitivity and provide them with justifications and explanations [39]. The satisfaction obtained from these opportunities to perform can be constructive in the fairness perception.

\section{RESEARCH METHODOLOGY}

As there have been few studies on the relationship between managerial practices and the level of perceived fairness, we opted for an exploratory case study design. One of the important benefits of using a qualitative method is that it will improve the ability of not only interpreting the events but also comprehending how and why the same events can be interpreted in a different, sometimes even conflicting manner, by different team members working for different organizations [40]. In the context of inter-organizational projects, the managerial practices adopted could raise different perception of fairness for members. So a qualitative method can be useful to document the perspectives and interactions among members from different organizations. Moreover, process research gives us an insight in the network of choice and implementation processes that are enacted by managers [41]. A single case can be a powerful tool to reach that target [42].

Based upon the earlier discussions the following preliminary conceptual framework is used (see Fig. 1).

Our case study will detail the efforts of Company Alpha, which is a multinational firm active in the telecom industry, and its collaboration with Company Beta, which is a firm working in the software industry. This case will highlight how the two firms managed to work together in the development of new interface software. The inter-organizational project team consisted of 10 members, which included a project manager and five members from Company Alpha and four members from Company Beta.

We have used the triangulation method to achieve a deep understanding of the case [42]. This research involved formal interviews, document collection, interpretation of participants' interviews and the secondary sources of information which were company documents, Intranet and Internet information and email communication. Initial contact with Company Alpha was made through the company's Director of the Department of Research and Innovation. This initial meeting resulted in a site visit to Company Alpha's office, tours of the innovation facilities, introduction to, and interviews with team members of the project under study.

This research is interpretative in that we attempt to understand phenomena through the meanings participants assigned to them [40]. Interviews were conducted with all the members of the project team which included a project manager and 2 project leaders. The interpretative methodology helped to gain knowledge of the details of Company Alpha's inter-organizational engagements through social constructions such as language, consciousness, shared meanings, documents and other artifacts' [43].

In this study interviews with 10 participants were conducted on a one-to-one basis. . Each member was interviewed once and at the end of the project. Detailed notes were taken during these interviews, which were then analyzed. In total, approximately 10 hours of interviews were conducted. The interview reports were returned to the project manager and the two project leaders for review. Additionally, the project provided significant documentation including emails of engagement, internal quality assurance documents, internal metrics and performance analysis. An overview of the interviewees is given in Table $\mathbf{1}$.

\section{Data Analysis}

The transcripts of each interview session constituted the recorded information that we analyzed. These interview reports were returned to member1, member 2 and member 7 for review. These reviewed reports were subsequently 


\section{Managerial practices}

- Relationship oriented practices

- Task oriented practices

\section{Perceived fairness}

- Distributive justice

- Procedural justice

- Interactional justice

Fig. (1)._Preliminary research model.

Table 1. Overview of the Interviewees

\begin{tabular}{|c|c|c|c|}
\hline Interviewee & Responsibility & Function & Company \\
\hline \hline Member1 & Project Manager & Ensures that the project meet expectations for scope, schedule and quality & Company Alpha \\
\hline Member2 & Senior Systems Analyst & Carries out researching, planning and recommending software and system & Company Alpha \\
\hline Member3 & Programmer Analyst & Executes complex testing, support and troubleshooting functions & Company Alpha \\
\hline Member4 & Programmer Analyst & Operates design and development of software programs & Company Alpha \\
\hline Member5 & Research Analyst & Performs program evaluation, qualitative analyse, design and evaluation, & Company Alpha \\
\hline Member6 & Evaluation Analyst & Develops and execute test plans, test cases and test scripts & Company Alpha \\
\hline Member7 & Senior Analyst & Conducts organized analytical assessments and evaluations and assists & Company Beta \\
\hline Member8 & Software Analyst & Performs proper software analysis and resolution activities & Company Beta \\
\hline Member9 & Systems Analyst & $\begin{array}{c}\text { Does the implementation and evaluation of system programs by } \\
\text { designing, measuring and monitoring process }\end{array}$ & Company Beta \\
\hline Member10 & Programmer Analyst & $\begin{array}{c}\text { Performs the programming and analysis duties in support of various } \\
\text { phases of systems generations }\end{array}$ & Company Beta \\
\hline
\end{tabular}

segmented, categorized, coded, and revised in order to make sense of them within the participants' own understandings. Categorizing involved segmenting the commentary into a meaningful unit of discourse (i.e., either a single statement or several people's comments about a single idea) called a strip. A strip can be an observable act, an interview, an experiment, a document, a comment, or any other bounded phenomenon against which the researcher tests his understanding [44]. An example of a strip consisting of two comments is the following:

Member 7: I engaged in coffee sessions in which conversations went into many personal details. We shared a laugh on many occasions, which was certainly a relief.

Member 3: We made sure that the external employees were invited to get-together parties and happy hours. It helped the team to come together.

Subsequent to the categorization of the transcripts into strips, each strip was coded. This was a process of reading the text strips and assigning provisional labels with respect to the content of the exchange. The labels assigned to strips summarized the theme of the strip as shown in the following examples:

Mechanisms exist to improve the interest of the external members in the project.

\section{Mechnisms exist for the external members to seek information.}

Mechnsims exist for the portioning of the isssues handled in the project.

We then employed the interpretive process to understand the meaning of the textual transcripts that resulted.
We employed an iterative process to interpret the meaning of the information exchanges. While reading the interview transcripts, we adjusted our perspective about the features of the information contained in them. When a strip did not agree with the expectation represented in the the initial plane of understanding there had to be a breakdown of that initial schema of understanding. By adjusting the schema and by revising her knowledge about the meaning of strips contained in the interview transcripts a resolution was reached. This progression of the revisions of schema went on until all of the strips were able to correspond with the schema that ultimately resulted. This schema provided the four managerial practices presented in further section.

Table 2 recapitulates the principles of interpretive research as described by Klein and Myers (1999) and shows how they are used in this case study.

Table 3 summarizes the research techniques those were applied for assuring the quality of the empirical study in line with $[45,46]$.

\section{PROJECT DESCRIPTION}

For this project, Company Alpha, who is the client, chose to have outsourcing collaboration with Company Beta, who is the vendor, because of its specific competences. This project required Beta to design and create the embedded software intended to control the steering systems and interface. The project involved new software tools, interface systems and processes for both Company Alpha and Beta. The generation of systems software needs a specialized skill set and domain knowledge. Systems software is different from the other software. This software is used when any device has to interact with the environment. The response time, power 
consumption and correct interfacing with the external environment are important. Besides the coding skills, systems software development requires additional skills not readily available in Company Alpha. Inherent in the successful creation of systems software is an intricate and detailed knowledge of the equipment that will house and interact with the software, which was available at Company Alpha.

The establishment of fairness among members was essential for the studied project to be successful considering the importance of open information sharing. The next section details the managerial practices adopted for the establishment of perception of fairness among members. This classification of managerial practices was based upon the transcripts of the interviews conducted.

\section{MANAGERIAL PRACTICES IDENTIFIED}

Having used the interpretative method to reveal the major managerial practices that were followed in the project studied, the interpretive process was employed to understand the meaning of the data that resulted from the interviews conducted.

\section{Managerial Practice 1: Integrating External Members}

This practice concentrates on improving the interest of the members by focusing firstly on relationship oriented practices in the project context. This practice was put forward with the objective of achieving cohesion between the external and internal members of the team. Different initiatives toward team building tried to stimulate the networking among team members. Joint social events helped them to create a unified group with common goals. In addition this practice involved the task oriented managerial practices of planning as well as clarifying roles and objectives.

The enhancement of social relationships is one way to encourage interactional justice.

In prior projects, Company Alpha found it difficult to integrate the external members into its culture and social systems. As reported by project manger, there were prior instances of open resentment between external members and internal members who would never have engaged in similar behavior with their colleagues. Therefore in the project under study, Company Alpha made a concerted effort to promote and to make possible a smooth progress of integration. This integration began with exchange of information in an 'induction session'. As mentioned by the project manager: 'When we summon the external members in for the induction session, they are assembled with our members who will be involved in the project along with them. They're in the session understanding the details and being counselled by the leads.'

Over time, regular follow up meetings led to mutual understanding and collective action. The activity was not limited to information exchange. It was also used to create a team atmosphere that lasted through the completion of the project. For instance, member 7 from company Beta was of the opinion that this improved his relationship with members of company Alpha. This in turn helped him to fulfill the demands of his role in the project and meet the project obliga- tions. Initially member 7 experienced these meetings as quite formal containing little self-disclosure, such as brief memorandums describing specific business issues. As the project made progress member 7 found there were more informal interacting moments revealing more personal information and he got a more positive feeling of the relationship. Also the members of Company Alpha stressed that the integration was successfully achieved. As mentioned by member 3: 'I think that our deliberate attempt not to erect barriers among the people who are here, facilitated to promote the building of positive relationships.'

This effort to increase the social interaction between internal and external employees paid dividends to the project. The line between external and internal members became blurry. The external employees were viewed by Company Alpha employees as team members and they all shared in the successes and challenges of the project. According to member 9 of Company Beta: 'Of all of our systems collaborators they have put the maximum effort to make us have the sense of being part of the team. Our evaluation for working on this project demonstrates the worth of this integration. Our members have internalised their mission and values. It is an extremely esteemed task to work on this project.'

Therefore, it seems that these integration-oriented actions can increase harmony among the members, decrease the interpersonal differences and improve the inter-organizational bonding. Consequently this managerial practice increased interactional justice by stimulating coordination and understanding.

In addition this practice influenced the procedural justice as it laid a platform for expressing each team member's viewpoint to other members while at the same time examining such views critically. Openness to the external member's viewpoints is at the core of procedural justice in interorganizational projects as they have expectations of influencing the project progress. Inability within the project to provide such consideration will be perceived as a procedural impropriety and might thus be judged as unfair. As stated by member 7: 'I have to say that in this project my points of view were considered for various tasks we were involved in. Certainly there were many instances when my perspective was overridden but what was important for me was that even those rejections were after an open-minded discussion.' The team meetings organized on a regular basis as part of the integration practice provided a platform for all members to express their perspectives on task associated. Also the project manager ensured that all these perspectives were considered for discussion before acceptance or rejection. These meeting sessions gave opportunities for all the members to engage in the project development as well provided a means for the explanation on the course of action of the project activities. As said by the project manager: 'The value derived from this enhancement could progress into increasing commitment and cooperation. This in turn strengthened the processes of control and monitoring to be more organized and effective'. So this practice helped in developing procedural justice. 
Table 2. Review of the Interpretive Principles Utilized

\begin{tabular}{|c|c|}
\hline $\begin{array}{l}\text { Principles for the Evaluation of Interpretive field } \\
\text { Research }\end{array}$ & Evaluation in Current Case Study \\
\hline 1. The fundamental principle of the hermeneutic circle & $\begin{array}{l}\text { The inquiry was conducted with concentration on specific opinions on the fairness perception } \\
\text { within the project. This helped to keep the analysis effective and focused. It also made easier } \\
\text { to sort out what information was important to be elaborated. }\end{array}$ \\
\hline 2. The principle of contextualization & $\begin{array}{l}\text { The study conducted critical reflection of the historical background of the project. This made } \\
\text { it clear how the inter-organizational cooperationunder investigation emerged. This is } \\
\text { explained in the project description. }\end{array}$ \\
\hline 4. The principle of abstraction and generalization & $\begin{array}{l}\text { The significant point of this study is that theory from existing literature plays a vital function } \\
\text { in this interpretive research. We have mainly used the study of Bstieler (2006) }\end{array}$ \\
\hline 5. The principle of dialogical reasoning & $\begin{array}{l}\text { The contextual inquiry was performed with the intention of being open to new insights in the } \\
\text { project. There was no problem of adjusting the preconceptions as the picture of the project } \\
\text { became clearer. }\end{array}$ \\
\hline 7. The principle of suspicion & $\begin{array}{c}\text { During the contextual inquiry, the views experessed were actively deepened out by } \\
\text { challenging the interviewed members. They were confronted with opinions, which were } \\
\text { diverging and obtained from other members. }\end{array}$ \\
\hline
\end{tabular}

Table 3. Quality Assessment of Empirical Study

\begin{tabular}{|c|c|c|}
\hline Quality criterion & Requirement & Actions for Enhancement \\
\hline Internal validity & $\begin{array}{l}\text { Inferences are said to possess internal validity if a causal } \\
\text { relation between two variables is properly demonstrated }\end{array}$ & $\begin{array}{l}\text { Establishing relationships between managerial practices and } \\
\text { fairness perception whereby certain practices are shown to lead to } \\
\text { fairness perception }\end{array}$ \\
\hline External validity & $\begin{array}{l}\text { Inferences about relationships are said to possess } \\
\text { external validity if they may be generalized from the } \\
\text { unique settings }\end{array}$ & $\begin{array}{l}\text { Establishing the domain, namely the inter-organizational projects } \\
\text { to which the study's findings can be generalised }\end{array}$ \\
\hline Reliability & Reliability is measuring something consistently & $\begin{array}{l}\text { Collecting and analyzing of data was done concurrently in this } \\
\text { case study }\end{array}$ \\
\hline Content validity & $\begin{array}{l}\text { Content validity refers to the extent to which a measure } \\
\text { represents all facets of a given social concept }\end{array}$ & Multiple members interviewed within the case study. \\
\hline Construct validity & $\begin{array}{l}\text { Construct validity involves generalizing from the } \\
\text { conducted study to the concept of the study }\end{array}$ & $\begin{array}{l}\text { Multiple sources of evidence other than the interviews such as } \\
\text { company documents, Intranet and Internet information were } \\
\text { accessed in this case study }\end{array}$ \\
\hline
\end{tabular}

\section{Managerial Practice 2: Coordinating the Training Activi- ties}

This practice concentrates on improving the interest of the members by focusing on developing and mentoring practice .This practice was put forward with the objective of giving the members power to look for information required to perform their activities, to examine the improvement in project performance and to mend problems as they come up. These activities fall under the informing category of the task oriented managerial practice and under the supporting and networking category of the relationship oriented managerial practice.

Although combining the training of internal employees with external employees could generate risks such as revealing important business confidential matters, managers considered joint training sessions a must for two reasons. Firstly a large quantity of product and process understanding was required by the team to effectively develop the system. Secondly it was required to cultivate common objectives among the members. Company Alpha provided the external members with facility visiting sessions and training classes on application designs, assembly software, tools modeling products, operational manuals for devices, quality assurance processes, and an outline of all of the various products and platforms. According to the Project Manager: 'We certainly reaped the gains and true worth of rightly bringing those people here. We showed them the way our system operates and trained them along with our members which meant they were one team.'

The coordinated training sessions were platforms for open information sharing which offered the possibility for providing timely feedback to all the members. Receiving timely feedback about decisions is an important criterion by 
which to judge the fairness of the procedures in project activities. This is so because the feedback communicates to each member engaged and concerned with the project why the decisions are made as they are and why certain ideas and inputs may have been overridden in ultimate decisions. The external members appreciated to receive fast feedback. As stated by member7: 'My right to information was duly respected in the project though I came from another organization.' In addition, since many decisions are made by the management in private, the manager's justification and rationale for these decisions may be the primary basis on which members, especially the external, would perceive procedural fairness in inter-organizational projects. The coordinated training sessions gave opportunities for the manager to supply justifications for the decisions. As cited by member10: 'There was adequate time spent on us to elaborate to on the project decisions made which were going to affect my responsibilities. Though this is expected, it is not often that such expectations are met. But this time it was an exception.' This practice influenced interactional justice. It helped in putting forward that the procedures and criteria used in the decisions and their execution were impartial and in accordance with objective contractual specifications. As stated by member8: 'For most of us, being treated like the others was the hallmark of fair treatment. I always felt we were treated on the same level.'

Coordinating the training of external employees with internal training activities also improved teamwork, which promoted coordination, comprehension, and learning and thus helped reduce disputes and tensions among the members. As commented by the Project Manager: 'The training sessions were designed taking into considering the background and experience of the diverse team composition we had. Definitely the sessions were meant to groom the team as a whole and the results show that we succeeded in doing so.' Thus this practice helped in reciprocal learning and in reducing incongruities among members, which encourage cooperation leading to improved interactional justice.

\section{Managerial Practice 3: Packaging the Projects into Distinct Modules}

This practice involved the modularization of tasks to be completed in the project, leading to a reduced stress level. In software terminology, modules characterize the partitioning of issues being tackled. According to the project plan these tasks were to be completed on average in ten business days and they had well delineated purposes and requirements (problem solving practice which comes under the category of task oriented managerial practices). According to the Project Manager this method gave certain advantages: 'With this, each member had a sense of owenership for each assignment allocated to him or her. Also we could watch the project from a practical point of view. Through this approach, we got two advantages. First of all the amount of work amendments required was reduced significantly. Secondly the merit of functions also advanced noticeably.'

This practice had a positive side effect on the perceived fairness, in particular the interactional justice. First, it created a system of both strong and weak network ties. For example, an internal member 2 working closely on the project with external member 7 would develop strong ties. Such strong ties facilitated reciprocal information exchange as they had great motivation to be of assistance. At the same time, the internal member 2 also worked tangentially with external member 9. This created a weak tie with external member 9. Such weak ties facilitated the generation of new information by exposing the team to new development and implementation techniques. This increased the network utilization and thereby the opportunity for improving the interactions. This was supported by member 8: 'Actually, he (the manager) quite clearly states his intentions regardless of the fact we are not part of his company and he was making it clear that he expected the same from us. Though initially I was hesitating, when I was aware that he meant exactly what he said, I felt that I could respond in the same wavelength.'

It was reported, that this practice led to superior interactions among members involving open exchanges, well timed reponses, reciprocal reverence and interpersonal learning, which could drastically reduce the differences of opinions among them. Thus, this practice gave the provision for courtesy and mutual understanding, in the course of interpersonal treatment thereby influencing the interactional justice. There was no evidence to relate this practice to other dimensions of fairness namely procedural justice and distributive justice.

\section{Managerial Practice 4: Focus on the Long Term Reward}

This practice of rewarding concentrated on improving the interest of the members by influencing the relationship oriented practices of the project context. In order to stimulate the perception of fairness of both the internal and the external employees, the Project Manager clearly communicated the effects that the project could have on the career opportunities of Alpha's project members. For this purpose the project management evaluated the personnel management process and also the possible future projects which might evolve as offshoots from the existing one. The communication of this to Company Alpha members could help to create a positive image of their future career. Simultaneously, management started pinpointing to the members of Company Beta that the successful completion of the existing project could open up possibilities for further developments and improvement projects provided in Access Network. Such future projects definitely required the skills of the members from Company Beta involved in the current project. Thus the future projects could provide relevant and more responsible roles for these external members as well. A list of prospective research possibilities was generated. The project management built a business model that utilized as inputs the existing and previous business trends, the current internal resources and the anticipated requirements. This model along with the resources requirements in the related research domain was explicitly communicated to the internal and external members. As said by the Project Manager: 'We are focused on the next possibilities in the existing technology channel. Based on this we could pitch a potential demand on the number of programmers both in hardware and software, designers and also project leads required in the coming 3 to 4 years. Point to be noted here is that for each new member elevated to become a project lead there will be need for 4 or 5 members who could be designers or programmers to work under him. So the existing project was going to branch to several new intitiatives which required more teams to work.' 


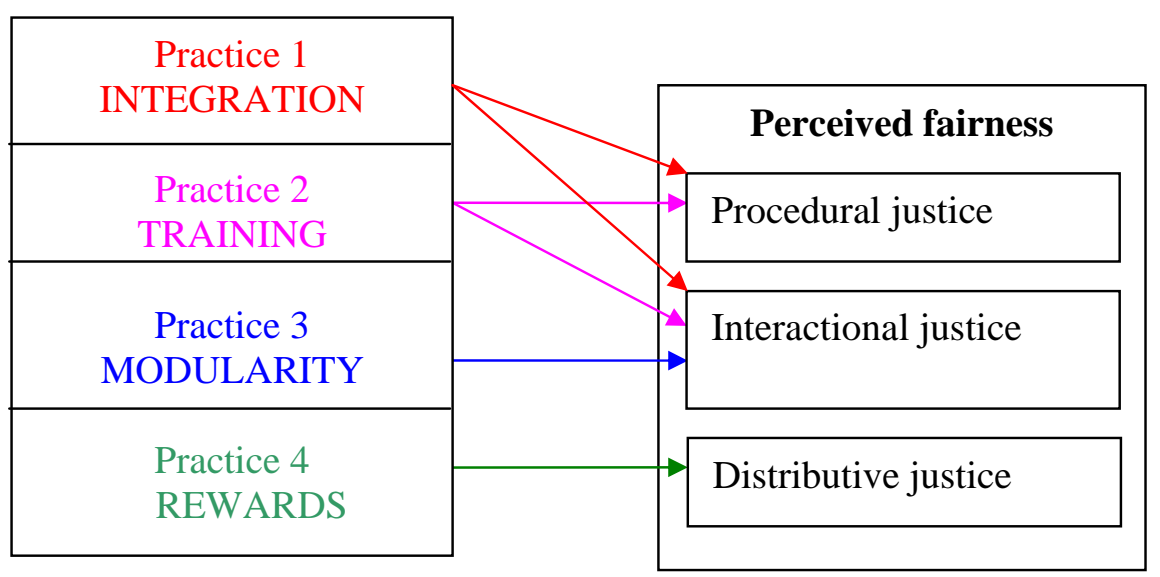

Fig. (2)._A refined framework.

For member1 for Company Alpha it was clear that the success of this project was not only going to reward him in the current scenario but also going to aid him having a faster career growth: 'There are 3 distinct projects which are already in the pipeline as an extension of this project. I am certain that with my experience and performance in this project I am getting a higher responsible role to play in one of them.' A similar positive statement was obtained from member7 of Company Beta as well: 'Before this project if you had ask me where my career was heading I would not have been able to give a clear answer. But now things are different. I can picture of a future of myself heading and managing larger teams working on Access Network Services.'

The open communication on the future innovation pipeline led to three positive side-effects. Firstly, the sense of concern that was creeping among internal team members regarding the potential loss of their own position due to a 'take-over' by the external organization disappeared eventually. Instead, a perception of fairness was established. Secondly, the feeling of worry that was crawling into the external members of being left out of their parent organization, Company Beta, was alleviated as well. Thirdly, this practice could ensure that the rewards of the project success were distributed fairly considering the needs of all the project members and a sense of distributive justice grew. As said by member4: 'After completion of this project I wanted to be involved in a project related to the activities of this one. Considering my performance of this project that need was fulfilled'. This was supported explicitly by members 5, 6, 8 and 9. Thus, this practice could ensure that the distributive rules of equity and equality were satisfied among the project members.

\section{DISCUSSION: REFINED FRAMEWORK AND PROPOSITIONS}

The above discussions of the four managerial practices, which drive perceived fairness, result in a refined framework and propositions as presented in Fig. (2).

While researchers have studied the practice of integrating the members within a project few have put forth specific significance of this practice in improving the dimensions of perception of fairness in an inter-organizational project. It can be understood from this case study that the integration of the external members into the inter-organizational project team influences their feeling of security and sense of confi- dence on how to perform in the project. These developments encourage the members to interact more regularly among each other [47]. This sense of confidence developed supports the improvement of discussions among members augmenting the feedback [48]. The feeling of security facilitates the revealing of relevant information which they would have hesitated to divulge in the beginning due to lack of assurance with the internal members [2]. Thus this feeling of security improves the perception of interactional justice within the team. Also the integration of the team gave opportunity for the external members to articulate their perspectives on the project activities to the entire team as they felt the confidence that they will be considered with required esteem. Such a platform for all members to express their perspectives on task associated helped to improve the perception of procedural justice within the team. The members will consider this facility inside the project to present a consideration of procedural rightness [3]. So the following proposition is set forth:

Proposition 1: The extent of integration of the external members into the inter-organizational project team is positively associated with the perception of procedural justice and interactional justice within the team.

Even as researchers have studied the practice of coordinated training in projects this study has attempted to look into this practice through the lens of perception of fairness. The case study showed that coordination of the training of external employees with internal training activities provided opportunities for self-disclosure among the members. Selfdisclosure refers to the volume of relevant information that is conveyed which the other party would otherwise not have been able to access [49]. Thus self-disclosure improves the perception of interactional justice. Also this practice created a sense among the members that the procedures followed were transparent, adjustable, and unbiased to each member. These are essential criteria to attain procedural justice [3]. This practice could also ensure that the members felt that interpersonal treatment and information exchange across them were fair. Such interpersonal sensitivity is necessary to achieve interactional justice [8]. Hence it is proposed:

Proposition 2: The extent of coordination of the training of external employees with internal training activities is positively associated with the perception of procedural justice 
and interactional justice in the inter-organizational project team.

Unitization of project into distict modules in a significant practice studied in researches, especially in those focused on new product development. In this study this practice is examined with its relevance on fostering the perception of fairness in inter-organizational project. The case study revealed that the packaging of the project into distinct modules led to the improvement of the personal interactions among the members. Such personal interactions lead to mutual understanding, mutual respect and higher quality of interpersonal treatment. This practice also facilitated reciprocal information exchange as it created strong ties among the members. This reciprocity feature helps in the development of improved interactions [48]. As such these conditions seem necessary requirements to have perception of interactional justice among members [3]. Through the unitizing of work into small objects the project network developed weak ties among members working in different modules. Such weak ties allowed the exchange of new relevant information. As a result the following proposition is suggested:

Proposition 3: The packaging of the inter-organizational projects into distinct modules facilitates the perception of interactional justice within the team.

The practice of focusing on long term rewards in projects has been examined in previous studies. This study further supports the importance of this practice in interorganizational projects by attempting to elaborate on its influence upon the perception of fairness. The case study has shown that the practice of presenting the significance of this project in the career of the project members created the sense that it is a highly rewarding project to be involved in. Secondly the clarity of the possible rewarding career generated an opinion of fairness in the achievement of professional enhancement. This perception is fundamental to distributive justice [3]. Within this project, as explained in previous section this practice positively influenced the basic distributive justice principles of equity and equality. So it is proposed:

Proposition 4: Highlighting career rewards will improve the perception of distributive justice in the team.

\section{LIMITATIONS}

While additional research is needed to determine how the dimensions of perceived fairness and managerial practices are generalizable across firms and industries, the current study does show the importance in understanding interorganizational projects giving importance to perceived fairness. In the case of project between Company Alpha and Beta, the study could confirm that the nurturing of perceived fairness was certainly seen as a necessary force to achieve success. We hope that more case studies are analyzed in which researchers show how to operationalize the findings on perception of fairness in projects. Further research studies need to validate the propositions derived from our case study which has limitations such as a retrospective approach and a limited though highly triangulated case study setting. Further studies are needed to determine how various managerial practices aimed at improving the perception of fairness are depending on different types of contingencies such as (1) different forms of inter-organizational cooperative activities (eg, product vs process innovation), (2) specific industries (eg, high-technology vs low-technology), (3) organizational or national cultures.

The research was conducted within a specific industry and as such findings may not be generalizable to other cases. The findings however offer a different view on the complex relationships between managerial practices and perceived fairness components and illuminate the potentials of managerial practices in capitalizing perceived fairness.

\section{CONCLUSION AND IMPLICATIONS}

Our research goal was to gain an insight in the managerial practices which help to achieve perception of fairness in inter-organizational projects. In our exploratory case study, it was clearly observed that some managerial practices were perceived as being important for the perception of fairness in the inter-organizational project. Company Alpha tackled major challenges in the successful completion of this interorganizational project. These demanded special efforts that made them follow certain managerial practices to ensure that the objectives of the project were fulfilled. We identified four specific managerial practices that improved and enriched the perception of fairness: (1) integration efforts, (2) training coordination of internal and external members, (3) splitting-up of the project in distinct modules and (4) showing the impact of the project performance on long term rewards.

This study puts forward that these managerial practices were valuable in the sense that they enhanced the perception of fairness amongst the project members. Insights in these managerial practices can help companies to more effectively build up and leverage competences in inter-organizational alliances.

This study on key managerial practices for the management of perception of fairness has important implications for inter-organizational research and practice. Firstly, this analysis shows that improvements in perceived fairness are significant outcomes of several managerial practices. Secondly, this study emphasizes the importance of attending to the multiple dimensions of perceived fairness (procedural, interactional and distributive) in the conception and execution of managerial practices. This way, project managers can neutralize hindrances in inter-organizational collaboration and even create synergies by simultaneously stimulating perceived fairness dimensions. Project managers should consciously plan and manage the different managerial practices. This aspect is a key challenge in open innovation endeavours.

We propose that managers should take note of the influence of the practices they undertake on perception of fairness within their teams. Managers should become aware of the manifold outcomes of the practices they put forward in interorganizational projects. For instance, a manager developing a new reward plan for internal members of the interorganizational project may overlook to consider the effect it can have on perceived fairness of the external members in the same team. The managers can ponder on the impact of their practices upon the perception of fairness that are relevant to them without reflecting upon the dimensions of fairness. They can execute practices that have unintended con- 
sequences for perception of fairness within the team. This definitely needs to be taken into consideration during the implementation of innovation projects.

Managers need to highlight that the integration of the external members into the inter-organizational project team influences their feeling of security and sense of confidence on how to perform in the project. In addition they should be aware that coordination of the training of external employees with internal training activities provided opportunities for self-disclosure among the members. Again it is critical for managers to note that the packaging of the project into distinct modules led to the improvement of the personal interactions among the members. Personal interactions can lead to mutual understanding, mutual respect and higher quality of interpersonal treatment. Finally the managers will have to have the understanding that the practice of presenting the significance of this project in the career of the project members created the sense that it is a highly rewarding project to be involved in.

\section{ACKNOWLEDGEMENT}

None declared.

\section{CONFLICT OF INTEREST}

None declared.

\section{REFERENCES}

[1] Vincent S. A transmutation theory of inter-organizational exchange relations and networks: Applying critical realism to analysis of collective agency. Hum Relat 2008; 61, 875-99.

[2] Newell S, Swan J. Trust and inter-organizational networking. Hum Relat 2000; 153, 1287-328.

[3] Luo Y. The independent and interactive roles of procedural, distributive, and interactional justice in strategic alliances. Acad Manage J 2007; 50, 644-64.

[4] Child J, Faulkner D. Strategies of cooperation: managing alliances, networks, and joint ventures. Oxford University Press. 1998

[5] Yukl GA. Leadership in organizations, prentice-hall, Englewood cliffs, NJ. 1994.

[6] Yukl G, Gordon A, Taber T. A hierarchical taxonomy of leadership behavior: integrating a half century of behavior research. J leadershp \& organ stud 2002; 9, 15-32.

[7] Lind EA, Tyler TR. The social psychology of procedural justice. Plenum: New York. 1988.

[8] Bies RJ, Moag JS. Interactional Justice: Communication criteria of fairness, in Roy J. Lewicki, Blair H. Sheppard \& Max H. Bazerman, (eds.), Research on negotiations in organizations, vol. 1, Greenwich, CT: JAI Press, 43-55. 1986.

[9] Atuahene-Gima K, Li H. When does trust matter? antecedents and contingent effects of supervisee trust on performance in selling new products in china and the united states. J Marketing 2002; 66, 6181.

[10] Kale PD, Singh H. Alliance capability, stock market response, and long term alliance success: the role of the alliance function. Strateg Manage J 2002; 23, 747-66.

[11] Ambrose ML, Arnaud A. Are procedural justice and distributive justice conceptually distinct? In J.A. Colquitt \& J. Greenberg (Eds.), Handbook of organizational justice. Mahwah, NJ: Lawrence Erlbaum Associates, 85-112. 2005.

[12] Luo Y. Procedural fairness and interfirm cooperation in strategic alliances. Strateg Manage J 2008; 29, 27-46.

[13] Luo Y. From gain-sharing to gain-generation: The quest for distributive justice in international joint ventures. J Int Manag 2009; 15, 343-56.

[14] Bstieler, L. Trust formation in collaborative new product development. J Prod Innovat Manag 2006; 23, 56-72.

[15] Sindhav B, Jonna H, Amy RR, Phani TA, Louis GP. The impact of perceived fairness on satisfaction: are airport security measures fair? does it matter? J Marketing \& Pra 2006; 14, 323 -35.
[16] Ambrose ML, Schminke M. Examining justice climate: Issues of fit, simplicity and content, In F. Dansereau \& F. J. Yammarino (Eds.), Research in multilevel issues. Elsevier. Oxford, England, 6, 397-413. 2007.

[17] Tyler TR. Psychological models of the justice motive: Antecedents of distributive and procedural justice. J Pers Soc Psychol 1994; 67, 850-63.

[18] Simons T, Roberson Q. Why managers should care about fairness: the effects of aggregate justice perceptions on organizational outcomes. J Appl Psychol 2003; 88, 432-43.

[19] Schwinger T. The need principle of distributive justice In H.W. Biernhoff, R.L. Cohen,and J. Greenberg (eds.), Justice in Social Relations: Critical Issues in Social Justice. New York: Plenum Press, 211-25. 1986.

[20] Cropanzano R, Bowen D, E \& Gilliland, SW. The Management of organizational Justice. Acad Manag Perspect 2007; 21, 34-48.

[21] Turel O, Yuan Y, Connelly CE. In justice we trust: predicting user acceptance of e-customer services. J manag inform syst 2008; 24,123-51

[22] Colquitt JA, Conlon DE, Wesson MJ, Porter CO L H, Ng KY. Justice at the millennium: A meta-analytic review of 25 years of organizational justice research. J Appl Psychol 2001; 86, 425-45.

[23] Roch SG, Shanock LR. Organizational justice in an exchange framework: clarifying organizational justice distinctions. J Manag 2006; 32, 299-322.

[24] Schminke M, Ambrose M L, Cropanzano RS. The effect of organizational structure on perceptions of procedural fairness. J Appl Psychol 2000; 85, 294-304.

[25] Kim WC, Mauborgne RA. Procedural justice and managers' inrole and extra-role behavior: The case of the multinational. Manag Sci 1996; 499-515.

[26] Leventhal GS. What should be done with equity theory? New approaches to the study of fairness in social relationships. In K. Gergen, M. Greenberg and R. Willis (eds), Social Exchange:Advances in Theory and Research. Plenum Press, New York, pp. 27-55. 1980.

[27] Kim WC, Mauborgne RA. Procedural justice, strategic decision making and the knowledge economy. Strateg Manag J 1998; 19, 323-38.

[28] Bies RJ. Interactional (in) justice: The sacred and the profane in J. Greenberg \& R. Cropanzano (Eds), Advances in organizational justice. Stanford, CA: Stanford University Press, 89-118. 2001.

[29] Skarlicki DP, Folger R. Retaliation in the workplace: The roles of distributive, procedural, and interactional justice. J Appl Psychol 1997; 82, 434-43.

[30] Liao H, Rupp DE. The impact of justice climate and justice orientation on work outcomes: a cross-level multifoci framework. J Appl Psychol 2005; 90, 242-56.

[31] Colquitt JA, Shaw JC. How should organizational justice be measured, In J Greenberg, J Colquitt, Handbook of organizational justice, Mahwah, NJ: Lawrence Erlbaum Associates, 113-34. 2005.

[32] Cropanzano R, Slaughter JE, Bachiochi PD. Organizational justice and black applicants' reactions to affirmative action. J Appl Psychol 2005; 90, 1168-84.

[33] Saunders MN, Thornhill A. Organisational justice, trust and the management of change: An exploration. J Pers Rev 2003; 32, 360 75.

[34] Barringer BR, Harrison, JS. Walking a tightrope: creating value through interorganizational relationships. J Manag 2000; 26, 367 403.

[35] Blake RR, Mouton JS. The new managerial grid. Houston, TX: Gulf. 1978.

[36] Korsgaard MA, Sapienza HJ, Schweiger DM. Beaten Before Begun: The role of procedural justice in planning change. J Manag 2002; 28, 497-516.

[37] Konovsky MA. Understanding procedural justice and its impact on business organizations. J Manag 2000; 26, 489-511.

[38] Barden JQ, Steensma HK, Lyles MA. The influence of parent control structure on parent conflict in Vietnamese international joint ventures: An organizational justice-based contingency approach. J Int Bus Stud 2005; 36, 156-75.

[39] Cropanzano R, Prehar C, Chen PY. Using social exchange theory to distinguish procedural from interactional justice. Group Organ Manage 2002; 27, 324-51. 
[40] Klein H, Myers M. A set of principals for conducting and evaluating interpretive field studies in information systems. MIS Quart 1999; 23, 67-94.

[41] Pettigrew AM. The character and significance of strategy process research. Strateg Manage J 1992; 13, 5-16.

[42] Siggelkow N. Persuasion with Case Studies. Acad Manag J 2007; 50, 20-4.

[43] Boudreau MC, Gefen D, Straub, DW. Validation in information systems research: a state of the art assessment. MIS Quart 2001; 25, 1-16.

[44] Trauth EM, Jessup LM. Understanding computer-mediated discussions: positivist and interpretive analyses of group support system use. MIS Quart 2000; 24, 43-79.
[45] Eisenhardt KM. Building theories from case study research. Acad Manag Rev 1989; 44, 532-50.

[46] Yin RK. Case study research design and methods. Sage Publications Inc. 2003.

[47] Dirks KT, Ferrin DL. The role of trust in organizational settings. Organ Sci 2001; 12, 450-67.

[48] Holden MT, Toole T. A quantitative exploration of communication's role in determining the governance of manufacturer retailer relationships. Ind Market Manag 2004; 33, 539-48.

[49] Barry B, Crant MJ. Dyadic communication relationships in organizations: An attribution/ expectancy approach. Organ Sci 2000; 11, 648-64.

(C) Prasad et al.; Licensee Bentham Open.

This is an open access article licensed under the terms of the Creative Commons Attribution Non-Commercial License (http://creativecommons.org/licenses/by-nc/3.0/) which permits unrestricted, non-commercial use, distribution and reproduction in any medium, provided the work is properly cited. 